\title{
A change to the surgical safety checklist to reduce patient identification errors
}

\author{
Christopher L. Pysyk, MD, FRCPC
}

Received: 17 September 2017/Revised: 13 October 2017/ Accepted: 17 October 2017/Published online: 2 November 2017

(c) Canadian Anesthesiologists' Society 2017

\section{To the Editor,}

Most near misses and events with harm to a patient arising from identification (ID) errors are thought to be preventable. In a large Canadian tertiary care hospital, more than $6 \%$ of surgical patients had their ID bands removed - most commonly for vascular line access during their time in the operating room (OR). ${ }^{1}$ Not surprisingly, the competing and dynamic demands involved with providing intraoperative care may lead the OR team to defer replacing the ID band until later in the case. The risk of this practice is the propensity for timedeferred actions to be forgotten. Indeed, of those patients with ID bands removed, $60 \%$ did not receive a replacement band during the remainder of their time in the OR. ${ }^{1}$ If the ID band is not replaced before transferring the patient from the OR to the postanesthesia care unit (PACU) or intensive care unit (ICU), an impaired patient (pharmacologically from the anesthetic drugs and/or the surgical/disease state) arrives in a different clinical area with staff who are unable to confirm the patient's identity - one of the most critical aspects of subsequent care.

A series of cases involving patients arriving in the PACU without an ID band was entered in our hospitalwide, voluntary reporting system (Patient Safety Learning System, Datix Ltd., London, UK). Our multidisciplinary Quality and Patient Safety (QPS) Committee, consisting of an anesthesiologist and other allied perioperative health professionals, reviewed the cluster of these ID events and suggested a change to our Surgical Safety Checklist (SSC).
We sought an institutional ethics review and subsequently received a waiver for individual patient consent because of the quality improvement nature of the committee and its work.

Our checklist, modelled after the World Health Organization's SSC, ${ }^{2}$ consists of three parts: "before induction of anesthesia" (i.e., brief), "before skin incision" (i.e., time out), and "before patient leaves operating room" (i.e., debrief). Following QPS Committee discussion, we decided that the final (debrief) part of the SSC was a reasonable time point at which to verify that the patient is wearing an ID (and allergy) band before transferring him or her to a different care area (e.g., PACU or ICU). During the six months after this change to our SSC, and with similar OR case volumes, no further events involving arrival of patients in the PACU or ICU without an ID band were reported in our Patient Safety Learning System. According to the hierarchy of effective strategies to guard against system threats, checklists offer a more favorable approach than education or messaging alone. $^{3}$

This report highlights the utility of an established process - such as event review via a QPS Committee - to facilitate a local response to perioperative patient safety challenges.

Conflicts of interest None declared.

Editorial responsibility This submission was handled by Dr. Hilary P. Grocott, Editor-in-Chief, Canadian Journal of Anesthesia.
C. L. Pysyk, MD, FRCPC ( $₫)$

Department of Anesthesiology and Pain Medicine, The Ottawa

Hospital, Faculty of Medicine, University of Ottawa, Ottawa,

ON, Canada

e-mail: cpysyk@toh.on.ca 


\section{References}

1. Burrows JM, Callum JL, Belo S, Etchells E, Leeksma A. Variable pre-transfusion patient identification practices exist in the perioperative setting. Can J Anesth 2009; 56: 901-7.

2. World Health Organization. WHO Surgical Safety Checklist. Available from URL: http://www.who.int/patientsafety/ safesurgery/checklist/en/ (accessed October 2017).
3. Trbovich $P$, Shojania $K G$. Root-cause analysis: swatting at mosquitoes versus draining the swamp. BMJ Qual Saf 2017; 26: 350-3. 